\title{
Criopreservación de estadios iniciales de gametofitos de Macrocystis pyrifera (Laminariales, Ochrophyta) en condiciones controladas de laboratorio
}

Cryopreservation of early stages of Macrocystis pyrifera gametophytes (Laminariales, Ochrophyta) under controlled laboratory conditions

\author{
María Inés Piel ${ }^{1}$, Marcela Avila ${ }^{1}$ y Angélica Alcapán ${ }^{1}$
}

${ }^{1}$ Instituto de Ciencia y Tecnología, Universidad Arturo Prat, Ejercito 443, Puerto Montt, Chile. maria.piel@unap.cl

\begin{abstract}
Macrocystis pyrifera is an economically important species for alginate production and as feed in the abalone industry. High demand for the product, both on national and international markets, makes these species vulnerable, putting natural populations at risk. The aim of this study was to apply cryopreservation techniques to M. pyrifera gametophytes in the laboratory and evaluate their effect on gametophyte development and maturity and on the subsequent growth of juvenile sporophytes. To this end, gametophytes obtained in laboratory cultures were frozen in liquid nitrogen and then defrozen, in order to restart their growth under controlled light, photoperiod and temperature conditions. Thirtyfive days after defreezing, the gametophytes grew normally and matured sexually, differentiating in to male and female gametophytes (53 and $47 \%$, respectively). Once fertilized, the growth and development phase of juvenile sporophytes begins, reaching an average daily growth rate of $10.4 \%$. Results indicate that cryopreservation is a successful preservation technique, recommended for maintaining M. pyrifera gametophyte stock under laboratory conditions for prolonged periods.
\end{abstract}

Key words: Gametophytes, cryopreservation, culture, Macrocystis pyrifera, brown seaweeds

\begin{abstract}
Resumen.- Macrocystis pyrifera es una especie de importancia económica utilizada para la producción de alginatos y como alimento en la industria de los abalones. La alta demanda del producto en los mercados tanto nacionales como internacionales hace vulnerable a esta especie poniendo en riesgo la mantención de sus poblaciones naturales. El objetivo de este trabajo fue aplicar técnicas de criopreservación de gametofitos de M. pyrifera en el laboratorio evaluando su efecto en el desarrollo de la maduración, y en el posterior crecimiento de esporofitos juveniles. Para ello, gametofitos obtenidos en cultivos de laboratorio fueron congelados en nitrógeno líquido y descongelados para reiniciar su crecimiento bajo condiciones controladas de luz, fotoperiodo y temperatura. Luego de 35 días de ocurrida la descongelación, los gametofitos crecieron de manera normal y maduraron sexualmente, diferenciándose en gametofitos masculinos y femeninos ( 53 y $47 \%$, respectivamente). Una vez producida la fecundación, esporofitos juveniles iniciaron su crecimiento y desarrollo, alcanzando una tasa promedio de crecimiento diario de $10,4 \%$. Los resultados indican que la criopreservación es una técnica de preservación exitosa y recomendable para la mantención prolongada de stock de gametofitos de $M$. pyrifera en condiciones de laboratorio.
\end{abstract}

Palabras clave: Gametofitos, criopreservación, cultivo, Macrocystis pyrifera, algas pardas

\section{INTRODUCCIÓN}

A nivel mundial se han incrementado las aplicaciones de macroalgas rojas y pardas para diversos usos, tales como gastronomía, alimentación animal, industria farmacéutica, biocombustibles y fertilizantes, entre otros (Zimmermann et al. 2003, 2005, 2007, Mansilla \& Avila 2011). En forma paralela el uso de algas en la industria de los hidrocoloides si bien se incrementa año tras año, en la última década su uso ha disminuido (Bixler \& Porse 2011). En Chile, las algas pardas tales como Macrocystis pyrifera y Lessonia spp. son altamente explotadas desde praderas naturales y anualmente se extraen sobre 250.000 ton húmedas. Dado el alto nivel de explotación de estas especies, Macrocystis pyrifera ha sido utilizada como modelo de estudio para establecer un manejo sustentable de este recurso algal (Vásquez et al. 2012, Borras-Chávez et al. 2012).

Macrocystis pyrifera (Linnaeus) C. Agardh, 1820, se distribuye en Chile desde la Región de Valparaíso

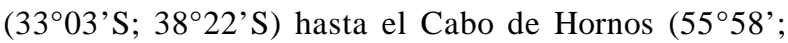
$67^{\circ} 17^{\prime}$ S) (Hoffmann \& Santelices 1997). Ha sido utilizada para la elaboración de ácido algínico (producción de alginatos) y en la industria farmacéutica (Westermeier et al. 2006, Mansilla \& Avila 2011). A nivel ecológico, esta especie forma bosques submarinos y es refugio, lugar de 
asentamiento y alimento para especies de invertebrados de importancia económica (Vasquez et al. 2012). Sin embargo, es altamente susceptible ante fenómenos naturales como es el evento El Niño (ENSO) (BorrasChávez et al. 2012). Por esta razón, ha sido importante estudiar diferentes formas de mantención de stock de gametofitos en laboratorios, para conservar material genético en medio sólido y/o líquido, con baja concentración de nutrientes y baja iluminación, los cuales pueden ser activados posteriormente para iniciar cultivos (Lüning \& Dring 1972, Lüning 1981, Westermeier et al. 2006).

Otra técnica utilizada para la conservación de stock algal ha sido la criopreservación, la cual consiste en la utilización de nitrógeno líquido para la mantención y la preservación de organismos por un largo periodo de tiempo, con bajo costo de mantención y almacenamiento en espacios reducidos (Kuwano et al. 2004). Sin embargo, no todas las experiencias realizadas han sido adecuadas en macroalgas de gran tamaño. Por ejemplo, Arbault et al. (1990) realizaron las primeras experiencias con gametofitos de Undaria pinnatifida, sin embargo estos ensayos no tuvieron éxito en la regeneración de gametofitos. Renard et al. (1992) informaron sobre la sobrevivencia de células gametofíticas de $U$. pinnatifida en nitrógeno líquido sin estimar la tasa de sobrevivencia. En este contexto, es necesario la generación de protocolos de criopreservación adecuados para cada modelo algal en diversos estados del ciclo de vida. El objetivo de este estudio fue evaluar el efecto de la criopreservación en estadios iniciales de Macrocystis pyrifera, tanto a nivel del desarrollo, maduración, fecundación de la fase gametofítica y posterior crecimiento de la fase esporofítica en condiciones controladas de laboratorio.

\section{MATERIALES Y MÉTODOS}

En la localidad de Chauman, Chiloé (414'ㄹ,96"S; $73^{\circ} 57^{\prime} 30,75^{\prime \prime W}$ ), se recolectaron esporofilas maduras de Macrocystis pyrifera las que fueron trasladadas hasta el laboratorio de macroalgas del Instituto de Ciencia y Tecnología, Universidad Arturo Prat, Puerto Montt, utilizando un contenedor hermético. Se seleccionaron trozos con soros esporangiales maduros, los cuales fueron lavados bajo un chorro de agua dulce. Posteriormente, el tejido fue enjuagados 4 veces con agua de mar filtrada $(0,45 \mu \mathrm{m})$ y esterilizada, dejando reposar sobre papel absorbente (deshidratación) por $4 \mathrm{~h}$. Pasado este tiempo, se llevaron los trozos de esporofilas a una cámara de flujo laminar horizontal (Labconco), se retiraron los trozos de frondas del papel absorbente y se cortaron trozos fértiles de 1 a $2 \mathrm{~cm}^{2}$, los cuales se dispusieron dentro de bolsas plásticas transparentes con agua de mar estéril y medio de cultivo Provasoli. A los $30 \mathrm{~min}$ se tomó una alícuota de $2 \mathrm{~mL}$ y las zoosporas recién liberadas se observaron en un microscopio binocular (Zeiss ${ }^{\circledR}$ AXIO Lab A1). Se retiraron los trozos de esporofilas de las bolsas plásticas, las cuales se trasladaron a una cámara de cultivo en condiciones controladas de fotoperiodo de día largo (16:08; L:O), temperatura de $10 \pm 2^{\circ} \mathrm{C}$ y una intensidad de luz fría de $35 \mu \mathrm{mol} \mathrm{m} \mathrm{m}^{-2} \mathrm{~s}^{-1}$

\section{Criopreservación}

Después de 7 días de iniciado el cultivo, se tomó una muestra de gametofitos iniciales en germinación (Fig. 1) para el inicio de la prueba de criopreservación. En cada tubo criogénico de $1,7 \mathrm{~mL}$ de capacidad, se agregó 0,75 $\mathrm{mL}$ de solución de gametofitos en germinación, más 0,75 $\mathrm{mL}$ de solución crioprotectante compuesta en relación 1:1 por Dimetil Sulfoxido, DMSO + HEPES. Los tubos criogénicos se colocaron en una bandeja con 81 celdas (para 81 criotubos) y se realizó una precongelación en un freezer convencional $\left(-18^{\circ} \mathrm{C}\right)$ por $30 \mathrm{~min}$, y posteriormente fueron introducidos en un tanque criogénico Taylor Warton LS 3000 (Taylor-Wharton International LLC $^{\odot}$ ) a una temperatura de $-196^{\circ} \mathrm{C}$.

\section{Descongelación}

Después de 13 días de iniciada la criopreservación, se seleccionaron al azar 5 tubos criogénicos del tanque, los cuales fueron descongelados. Para esto, los tubos fueron dispuestos en un recipiente plástico a baño maría por 1

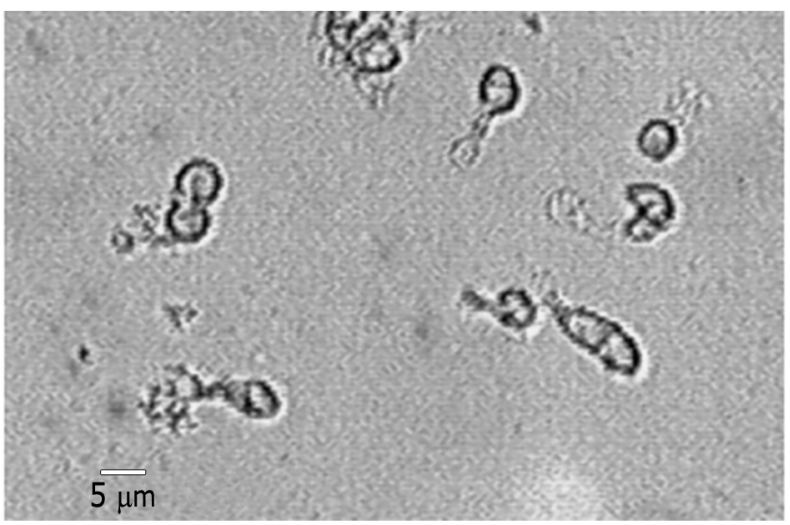

Figura 1. Germinación de los gametofitos iniciales de Macrocystis pyrifera con 7 días de cultivo. Imagen obtenida bajo microscopio invertido (40x) / Germination of early gametophytes of Macrocystis pyrifera with 7 days of culture. Photo under inverted microscope (40x) 
min $\left(38^{\circ} \mathrm{C}\right)$, y posteriormente fueron rápidamente trasladados a un baño de agua dulce con hielo picado $\left(4^{\circ} \mathrm{C}\right)$ por $1 \mathrm{~min}$. Dentro de la cámara de flujo laminar, se diluyeron las esporas de $1,5 \mathrm{~mL}$ a $4,5 \mathrm{~mL}$ en tubos Eppendorf, con medio de cultivo Provasoli y se centrifugaron por $5 \mathrm{~min}$ a $1000 \mathrm{rpm}$. Posterior a la centrifugación, se distribuyó el contenido de los 5 criotubos en 3 bolsas plásticas transparentes y se agregaron $100 \mathrm{~mL}$ de medio de cultivo Provasoli. Se incubó en la cámara de cultivo en las mismas condiciones iniciales (temperatura $10^{\circ} \mathrm{C}$; fotoperiodo 16:08 (L:O); irradianza de $35 \mu \mathrm{mol} \mathrm{m} \mathrm{m}^{-2} \mathrm{~s}^{-1}$. En forma paralela se mantuvieron cultivos control sin congelar y en las mismas condiciones de cultivo.

\section{FORMACIÓN Y CRECIMIENTO DE ESPOROFITOS}

Cuarenta y dos días post descongelación se comenzó con la evaluación de crecimiento de los esporofitos formados. Para esto, se aislaron 18 esporofitos de tamaños similares, los que se distribuyeron en 3 bolsas plásticas transparentes conteniendo cada una 6 esporofitos con $100 \mathrm{~mL}$ de agua de mar estéril enriquecida con Provasoli. Se mantuvieron en una cámara de cultivo bajo condiciones controladas (temperatura $10^{\circ} \mathrm{C}$; fotoperiodo 16:08 (L:O), y una intensidad de luz de $35 \mu \mathrm{mol} \mathrm{m} \mathrm{m}^{-2} \mathrm{~s}^{-1}$ ). Los muestreos de seguimiento se realizaron con una periodicidad semanal durante 6 semanas, mediante fotografías con una cámara fotográfica Canon ${ }^{\circledR}$ EOS Rebel XS, y la medición se realizó con el programa computacional Image J. Una vez que se obtuvieron las mediciones de longitud (crecimiento), se calculó la tasa de crecimiento diaria según la fórmula descrita por Yokoya et al. 2007, 2013: $\mathrm{TCD} \%=\left(\mathrm{Ln}\left(\mathrm{L}_{\mathrm{f}}^{*} \mathrm{~L}_{0}^{-1}\right)\right.$ $\left.* \mathrm{t}^{-1}\right) * 100$, donde: $\mathrm{Lf}=$ Longitud Final $(\mathrm{mm}) ; \mathrm{L}_{0}=$ Longitud Inicial $(\mathrm{mm}) ; \mathrm{t}=$ tiempo tratamiento 35 días.

\section{Resultados}

Antes (Fig. 2A) y después (Fig. 2B) de la criopreservación, los gametofitos fueron fotografiados, observándose estados iniciales de 1 a 2 células, similares en morfología en ambos casos. El tratamiento control muestra un desarrollo normal de gametofito con varias células (Fig. 2C).

A la cuarta semana de cultivo, después del periodo de criopreservación, se observó la formación de gametofitos femeninos y masculinos, claramente diferenciables por la morfología y tamaño de las células (Fig. 3A). Además, se observó una mayor abundancia de gametofitos masculinos (53\%) que femeninos (47\%). En los gametofitos femeninos fue posible diferenciar estados de maduración (Tabla 1), 29\% de gametofitos en desarrollo o aún inmaduros (solo células vegetativas), $9 \%$ de gametofitos con presencia de ovogonio o células huevos (Fig. 3B) y un $9 \%$ de esporofitos iniciales de 1 a 2 células. En los gametofitos masculinos no fue posible identificar estados de maduración y todos presentaron una morfología esférica (Fig. 3A). Una vez que maduraron, los gametofitos femeninos dieron origen a células huevos (Fig. 3B), posterior a la fecundación se observaron esporofitos iniciales. En general, se observó que los gametofitos femeninos siempre se encontraban al lado de al menos un gametofito masculino (Fig. 3A).

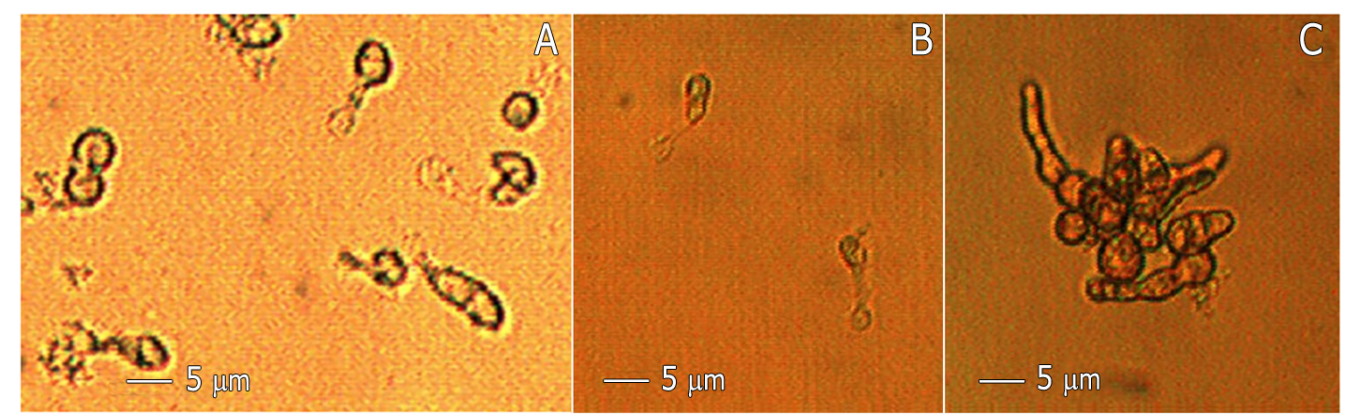

Figura 2. A) Gametofitos iniciales con 7 días de cultivo antes de ser criopreservados (40x), B) Gametofitos recién descongelados, después de 13 días en tanque de criopreservación (40x), C) Control (no congelado) después de 20 días de cultivo (40x) / A) Early gametophytes after 7 days of culture before being cryopreserved (40x), B) Early gametophytes unfrozen after 13 days in tank cryopreservation (40x), C) Control (not frozen) after 20 day of culture (40x) 


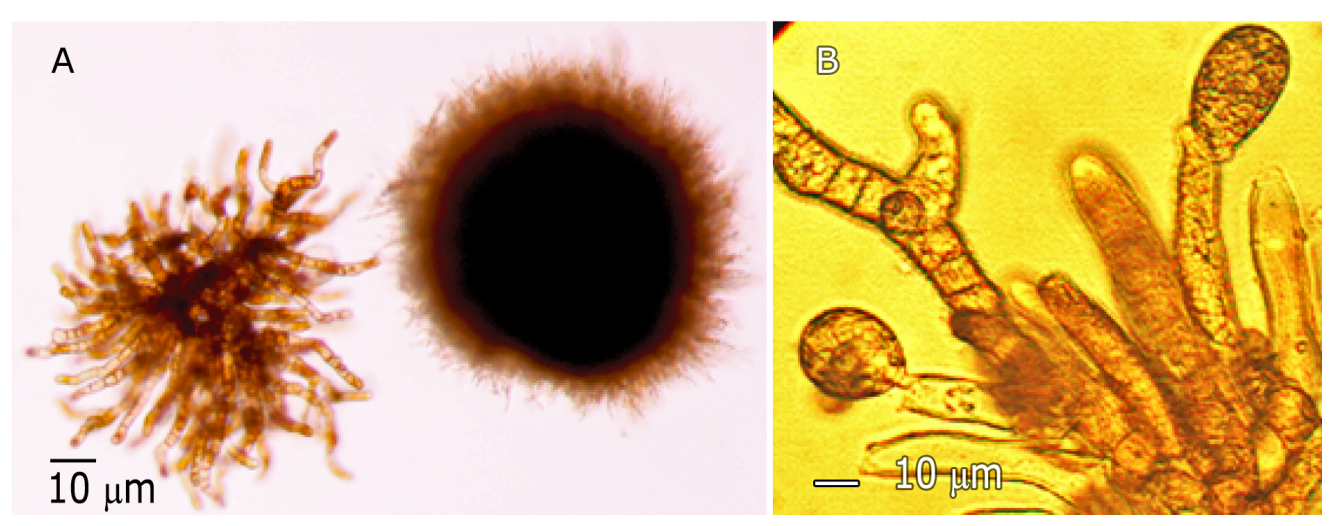

Figura 3. A) A la izquierda se observa un gametofito femenino con filamentos de mayor grosor y a la derecha un gametofito masculino (forma esférica) muy ramificado y de filamentos más angostos, a los 35 días post descongelación, (40x). B) Gametofito femenino maduro con oogonio (célula huevo) listo para ser fecundado y esporofito con 2 células 35 días post descongelación, (100x). Los cultivos fueron realizados bajo condiciones controladas [temperatura $10^{\circ} \mathrm{C}$; fotoperiodo $16: 08$ (L:0); irradiación $35 \mu \mathrm{mol} \mathrm{m}^{-2} \mathrm{~s}^{-1}$ ] / A) On the left a female gametophyte is observed with thicker filaments and right a male gametophyte with highly branched filaments with spherical shape, at 35 days post unfrozen, (40x); B) Female gametophyte with mature oogonio (egg cell) ready for fertilization and sporophyte with 2 cells 35 days post unfrozen, $(100 \mathrm{x})$. Culture controlled conditions [temperature $10^{\circ} \mathrm{C}$, photoperiod 16:08 (L:D), irradiation $35 \mu \mathrm{mol} \mathrm{m}^{-2} \mathrm{~s}^{-1}$ ]

Tabla 1. Tabla comparativa (\%) de presencia de los gametofitos 35 días post descongelación de los gametofitos iniciales de M. pyrifera / Comparative table (\%) of the presence of gametophytes after 35 days defrozen of early gametophytes of M. pyrifera

\begin{tabular}{lcc}
\hline & $\begin{array}{c}\text { Gametofitos } \\
\text { femeninos }\end{array}$ & $\begin{array}{c}\text { Gametofitos } \\
\text { masculinos }\end{array}$ \\
\hline Forma gametofito & Esférica & Esférica \\
Gametofitos en desarrollo (\%) & 29 & 53 \\
Células huevos u ovogonio (\%) & 9 & - \\
Esporofitos iniciales (\%) & 9 & - \\
Total & 47 & 53 \\
\hline
\end{tabular}

Tabla 2. Desarrollo y crecimiento de los esporofitos generados post criopreservación de gametofitos iniciales de M. pyrifera durante 6 semanas. Se incluye: longitud promedio $(\mathrm{mm})$, error estándar (EE) y tasa de crecimiento (\%) diario / Development and growth of sporophytes generated post cryopreservation of early gametophytes of $M$ pyrifera for 6 weeks; average length $(\mathrm{mm})$, standard error (EE) and daily growth rate (\%) are included

\begin{tabular}{ccccc}
\hline $\begin{array}{c}\text { Tiempo } \\
\text { (semanas) }\end{array}$ & $\begin{array}{c}\text { Días post } \\
\text { descongelación }\end{array}$ & $\begin{array}{c}\text { Longitud } \\
\text { promedio } \\
\text { semanal (mm) }\end{array}$ & $\begin{array}{c}\text { Error } \\
\text { stándar } \\
\text { (EE) }\end{array}$ & $\begin{array}{c}\text { Tasa de } \\
\text { crecimiento } \\
(\%)\end{array}$ \\
\hline T0 & 42 & 1,2 & $\pm 0,06$ & - \\
T1 & 49 & 3,2 & $\pm 0,2$ & 14,4 \\
T2 & 56 & 5,5 & $\pm 0,1$ & 11,0 \\
T3 & 63 & 10,0 & $\pm 0,3$ & 10,2 \\
T4 & 70 & 12,7 & $\pm 0,3$ & 8,5 \\
T5 & 77 & 17,4 & $\pm 1,2$ & 7,7 \\
\hline
\end{tabular}

A partir de la quinta semana post descongelación, se observaron esporofitos de más de 6 células, iniciando su desarrollo. La medición de los esporofitos se inició a 42 días post descongelación (T0), donde se observaron individuos juveniles con una longitud promedio de 1,2 \pm $0,06 \mathrm{~mm}$ y al T5 con una longitud promedio de 17,3 $\pm 1,2$ mm (Fig. 4) (Tabla 2). La tasa de crecimiento promedio para el periodo de 6 semanas fue de $10,4 \%$ crecimiento diario (Fig. 5).

\section{Discusión}

Se obtuvieron esporofitos de Macrocystis pyrifera a través de gametofitos en germinación criopreservados durante 13 días, demostrando que es factible utilizar esta técnica con esta especie. En el presente trabajo, se encontró que Macrocystis pyrifera obtuvo un $53 \%$ de gametofitos masculinos versus un $47 \%$ de presencia de gametofitos femeninos. Los gametofitos femeninos por lo general se encontraron muy próximos a los gametofitos masculinos, los que presentaron una morfología esférica. Zhang et al. (2007) mencionan que en cultivos criopreservados de Laminaria japonica se encontró una mayor proporción de gametofitos masculinos que de gametofitos femeninos, siendo que en la naturaleza deberían estar en una proporción de 50 a $50 \%$. Esto podría deberse a que los gametofitos femeninos responderían diferencialmente ante el proceso de la criopreservación. Muñoz et al. (2004) indican que gametofitos en estado perfectamente esféricos suelen tener una menor fertilidad 


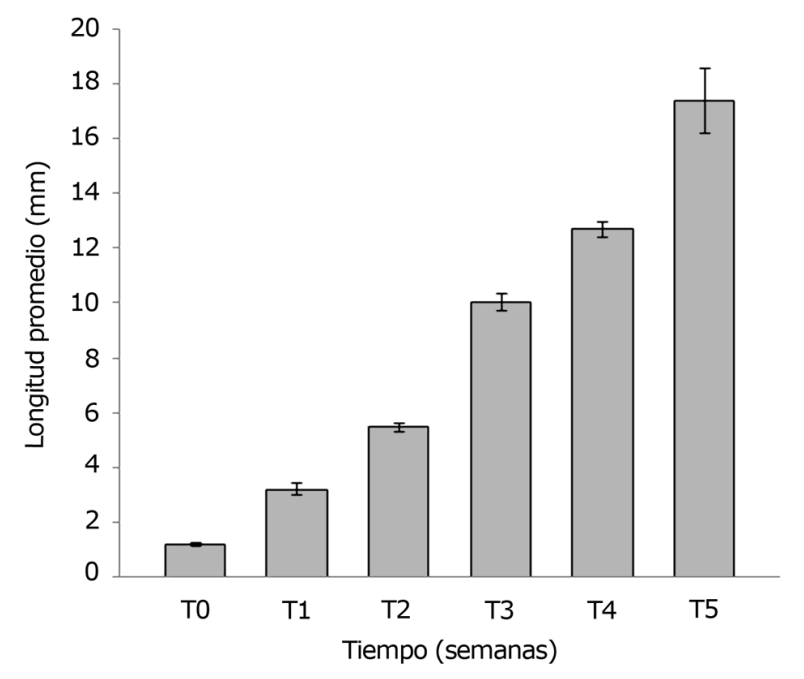

Figura 4. Crecimiento de esporofitos de Macrocystis pyrifera provenientes de cultivos criopreservados. Barra representa el crecimiento promedio de longitud $(\mathrm{mm})$, I representa el error estándar (EE). T representa al tiempo en semanas / Growth of Macrocystis pyrifera sporophytes from cryopreserved cultures. Bar represents the average growth in length $(\mathrm{mm})$, I represented the Standard Error (SE). T is represented for the time in weeks

que aquellos gametofitos unicelulares o que se encuentren fragmentados (pocas células). Sin embargo, a pesar que en la presente investigación se observaron gametofitos en estado esférico, sí se logró fecundación de células huevos, dando origen posteriormente a los esporofitos.

Palacios \& Mansilla (2003) muestran que en el desarrollo de los esporofitos de M. pyrifera, de la Región de Magallanes, la tasa de crecimiento varió entre 17 hasta $37 \%$. Sin embargo, trabajaron con distinto fotoperiodo (12:12 L:O), intensidad luminosa $\left(40 \mu \mathrm{Em}^{-2} \mathrm{~s}^{-1}\right) \mathrm{y}$ temperatura $\left(8 \pm 2{ }^{\circ} \mathrm{C}\right)$. Además, estos autores estimaron que la tasa promedio de crecimiento en estas condiciones fue de $8,35 \%$ diario. Los resultados del presente trabajo muestran que en el cultivo post-criopreservación la tasa de crecimiento diaria de esporofitos fue más alta que la descrita por Palacios \& Mansilla (2003) alcanzando un promedio de 10,37\%. Según Salazar (2011), se ha realizado criopreservación de esporofitos de Lessonia berteroana, alcanzando tamaños inferiores a los obtenidos en este estudio ya que los esporofitos a los 45 días midieron en promedio 2,7 $\mathrm{mm}$. En el presente trabajo los esporofitos de $M$. pyrifera criopreservados a los 45 días alcanzaron un tamaño promedio de $2 \mathrm{~mm}$ y a los 67 días $11,5 \mathrm{~mm}$, mientras que Salazar (2011) muestra que esporofitos criopreservados de L. berteroana sólo midieron $5,1 \mathrm{~mm}$ a los 67 días de cultivo. Por lo tanto, la información obtenida

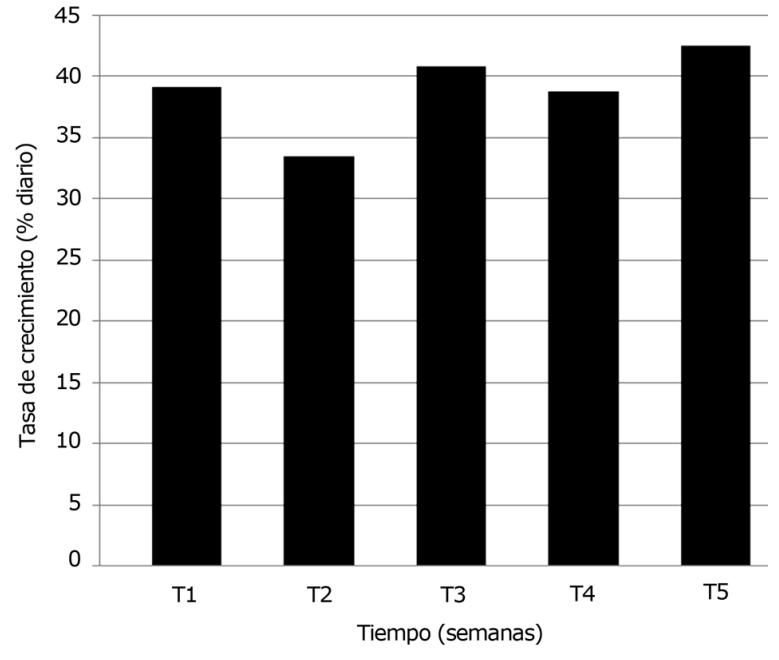

Figura 5. Tasa de crecimiento diario de esporofitos de Macrocystis pyrifera criopreservados. T representa al tiempo en semanas / Growth rate daily of sporophytes from Macrocystis pyrifera cryopreserved. $T$ is represented for the time in weeks

en el presente trabajo indica que la técnica de criopreservación fue exitosa y recomendable para la mantención prolongada de stock de gametofitos de $M$. pyrifera en condiciones de laboratorio.

\section{Agradecimientos}

Gracias a la confianza y aportes financieros otorgados por el Gobierno Regional de Los Lagos al proyecto FIC Código BIP 30128382-0. Se agradece la traducción del resumen a Susan Angus.

\section{LITERATURA CITADA}

Arbault S, P Renard, R Pérez \& R Kaas. 1990. Essai de cryoconservation des gametophytes de l'algue alimentaire Undaria pinnatifida (Laminariales). Aquatic Living Resources 3: 207-215.

Bixler HJ \& H Porse. 2011. A decade of change in the seaweed hydrocolloids industry. Journal of Applied Phycology 23: 321-335.

Borras-Chávez R, M Edwards \& JA Vásquez. 2012. Testing sustainable management in northern Chile: Harvesting Macrocystis pyrifera (Phaeophyceae, Laminariales). A case of study. Journal of Applied Phycology 24(6): 1655-1665.

Hoffmann A \& B Santelices. 1997. Flora marina de Chile central, 434 pp. Ediciones Universidad Católica de Chile, Santiago.

Kuwano K, S Kono, YH Jo, JA Shin \& N Saga. 2004. Cryopreservation of the gametophytic cells of Laminariales (Phaeophyta) in liquid nitrogen. Journal of Phycology 40(3): 606-610. 
Lüning K. 1981. Photobiology of seaweed: Ecophysiological aspects. Proceedings, International Seaweed Symposium 10: $35-55$

Lüning K \& M Dring. 1972. Reproduction Induced by blue light in female gametophytes of Laminaria saccharina. Planta 104: 252-256.

Mansilla A \& M Avila. 2011. Using Macrocystis pyrifera (L.) C. Agardh from southern Chile as a source of applied biological compounds. Revista Brasileira de Farmacognosia 21: 262-267.

Muñoz V, MC Hernández-González, AH Buschmann, MH Graham \& J Vásquez. 2004. Variability in per capita oogonia and sporophyte production from giant kelp gametophyte (Macrocystis pyrifera, Phaeophyceae). Revista Chilena de Historia Natural 77: 639-647.

Palacios M \& A Mansilla. 2003. Desarrollo de gametofitos y esporofitos de Macrocystis pyrifera (L) C Agardh (Laminariales: Lessoniaceae) de la Región de Magallanes en condiciones de laboratorio. Anales del Instituto de la Patagonia, Chile 31: 43-53.

Renard P, S Arbault, R Kaas \& R Pérez. 1992. A method for cryopreservation of the gamethophytes of the food alga Undaria pinnatifida (Laminariales). Comptes Rendus del Academie des Sciences, Serie III Sciences de la Vie 315(11): 445-451.

Salazar S. 2011. Criopreservación de esporofitos de Lessonia nigrescens. Tesis de Biólogo Marino, Universidad Arturo Prat, Iquique, $33 \mathrm{pp}$.

Vásquez J, N Piaget \& A Vega. 2012. The Lessonia nigrescens fishery in northern Chile: 'how to harvest is more important than how much you harvest'. Journal of Applied Phycology 24: 417-426.

Westermeier R, D Patiño, MI Piel, I Maier \& D Müller. 2006. A new approach to kelp mariculture in Chile: production of free-floating sporophyte seedlings from gametophyte culture of Lessonia trabeculata and Macrocystis pyrifera. Aquaculture Research 37: 164-171.
Yokoya NS, O Necchi-Junior, AP Martins, SF Gonzalez \& EM Plastino. 2007. Growth responses and photosynthetic characteristics of wild and phycoerythrin-deficient strains of Hypnea musciformis (Rhodophyta). Journal of Applied Phycology 19: 197-205.

Yokoya NS, M Ávila, MI Piel, F Villanueva \& A Alcapan. 2013. Effects of plant growth regulators on growth and morphogenesis in tissue culture of Chondracanthus chamissoi (Gigartinales, Rhodophyta) Journal of Applied Phycology 26: 819-829.

Zhang Q, Y Cong, S Qu, S Luo, X Li \& X Tang. 2007. A simple and highly efficient method for the cryopreservation of Laminaria japonica (Phaeophyceae) germplasm. European Journal of Phycology 42(2): 209-213.

Zimmermann U, U Leinfelder, M Hillgartner, B Manz, H Zimmermann \& F Brunnenmeier. 2003. Homogeneously cross-linked scaffolds based on clinical-grade alginate for transplantation and tissue engineering. In: Hendrich $\mathrm{C}, \mathrm{U}$ Nôth \& J Eulert (eds). Cartilage surgery and future perspectives, pp. 77-86. Springer, Heidelberg.

Zimmermann H, D Zimmermann, R Reuss, PJ Feilen, B Manz \& A Katsen. 2005. Towards a medically approved technology for alginate-based microcapsules allowing longterm immunoisolated transplantation. Journal of Material Science: Materials Medicine 16: 491-501.

Zimmermann H, F Wahlisch, C Baier, M Westhoff, R Reuss, D Zimmermann, M Behringer, F Ehrhart, A KatsenGloba, C Giese, U Marx, VL Sukhorukov, JA Vásquez, P Jakob, SG Shirley \& U Zimmermann. 2007. Physical and biological properties of barium cross-linked alginate membranes. Biomaterials 28: 1327-1345. 